\title{
Redox Cycling of Iron: Effects of Chemical Composition on Reaction Rates with Phenols and Oxygen in Model Wine
}

\author{
Thi H. Nguyen ${ }^{1}$ and Andrew L. Waterhouse ${ }^{1 *}$
}

\begin{abstract}
Wine oxidation is mediated by the redox cycling of iron between two oxidation states: the oxidation of iron(II) by oxygen and reduction of iron(III) by phenols. The effects of phenolic structure, $\mathrm{pH}$, and copper on the rates of these reactions were evaluated in model wine. In the absence of a nucleophile, pyrogallol exhibited greater reactivity with iron(III) than 4-methylcatechol. However, both compounds ultimately required aid from the nucleophile benzenesulfinic acid for unrestricted reduction of iron(III) to occur, illustrating the differential structure-dependent reactivities of phenols and the importance of nucleophiles to oxidation. It was hypothesized that the rate of oxygen consumption depends on the rate at which iron(II) is recycled from iron(III), though this was not found to be the case. While the rate of iron(III) reduction by 4 -methylcatechol in the presence of benzenesulfinic acid decreased at higher $\mathrm{pH}$, oxygen consumption was faster with increases in $\mathrm{pH}$. Furthermore, copper had no effect on the rate of iron(III) reduction but significantly increased the rate of oxygen consumption, indicating the two reactions may not occur synchronously despite being coupled through iron. Pseudo-first order rate constants for oxygen consumption were much lower than those for iron(III) reduction except when nucleophiles were absent (unlikely in wine), suggesting that iron(II) oxidation is the rate-determining reaction for the wine oxidation pathway. Therefore, the rate at which wine ages is likely limited by oxygen ingress, not chemical composition. However, the overall capacity of wine for oxidation may still depend on constituent phenols and nucleophiles, and a method to assess these factors is of interest.
\end{abstract}

Key words: iron, oxidation, oxygen, oxygen consumption rate, phenols, wine aging

The cascade of chemical reactions that occurs during wine aging starts with the oxidation of phenolic compounds into quinones coupled to the reduction of oxygen into hydrogen peroxide (Figure 1) (Danilewicz 2003, Waterhouse and Laurie 2006). It is now well-established that phenols are oxidized through iron, not by oxygen directly. While phenols are singlet compounds, molecular oxygen is a diradical existing in a paramagnetic, triplet ground state; thus, a direct reaction is spin-forbidden (Green and Hill 1984, Singleton 1987). The reaction cannot occur without the catalysis of transition metals, particularly iron, which circumvent the kinetic energy barrier associated with electron transfer (Miller et al. 1990). Studies in model wine have demonstrated that oxygen consumption by phenols cannot occur without the inclusion of iron (Danilewicz 2007, 2011, Danilewicz and Wallbridge 2010). Furthermore, slowing of oxidation reactions in model

${ }^{1}$ Department of Viticulture and Enology, University of California, One Shields Avenue, Davis, CA 95616.

*Corresponding author (alwaterhouse@ucdavis.edu; tel: 530-752-4777)

Acknowledgments: This work was supported by the American Vineyard Foundation and the ARCS Foundation Northern California Chapter. The authors declare no conflict of interest.

Manuscript submitted May 2020, revised Dec 2020, accepted Jan 2021

This is an open access article distributed under the CC BY license (https:// creativecommons.org/licenses/by/4.0/).

By downloading and/or receiving this article, you agree to the Disclaimer of Warranties and Liability. The full statement of the Disclaimers is available at http://www.ajevonline.org/content/proprietary-rights-notice-ajev-online. If you do not agree to the Disclaimers, do not download and/or accept this article. doi: 10.5344/ajev.2021.20024 and real wines has been observed with the addition of potassium ferrocyanide and other chelating agents, providing additional evidence for the central role of iron in wine oxidation (Danilewicz and Wallbridge 2010, Kreitman et al. 2013, Nguyen and Waterhouse 2019).

With iron acting as an electron carrier between phenols and oxygen, the initial reactions of wine oxidation are characterized by the redox cycling of iron between the iron(II) and iron(III) oxidation states. Evidence for the redox cycling of iron stems primarily from studies in which oxygen consumption was monitored in air-saturated model wine. Oxygen consumption occurred with iron(II) in proportion to the concentration of iron(II) used but did not occur with iron(III). Following this initial phase of oxygen uptake attributable to iron(II) oxidation, consumption continued only with the reduction of iron(III) to regenerate the necessary iron(II) (Danilewicz et al. 2008, Danilewicz and Wallbridge 2010, Danilewicz 2011). In real wines, iron(III) has been found to accumulate following exposure to excess oxygen, although iron(II) becomes the predominant species during aging (Danilewicz 2016, 2018, Nguyen and Waterhouse 2019), which suggests that reduction by phenols occurs in typical

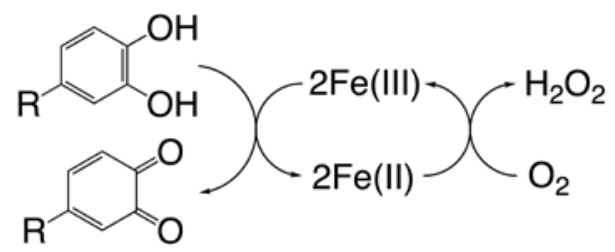

Figure 1 Phenol oxidation coupled to the reduction of oxygen via redox cycling of iron. 
storage conditions. These findings illustrate the key intermediary function of iron in the reaction between wine phenols and oxygen.

While oxygen consumption by iron(II) oxidation has been well studied, much less is known about the reciprocal process of iron(III) reduction by which wine phenols are oxidized. The rate at which this iron-phenol reaction occurs and the effect of chemical composition on this rate are unknown, as the measurement of this rate has never been attempted in wine. Iron speciation studies using excess oxygen to drive the oxidation of iron(II) showed that in most cases, the iron(II):iron(III) ratio stabilized before complete oxidation to iron(III) occurred (Danilewicz 2016, 2018, Nguyen and Waterhouse 2019); therefore, wine phenols should be able to reduce iron(III) at an observable rate that at least matches that of oxidation to effectively maintain a non-zero level of iron(II). Studying this reaction would provide a more complete understanding of wine oxidation and potentially explain in part the differences observed in ageability of wines, i.e., the capacity of wines to process oxygen and consequently undergo chemical changes during aging. Phenols are the primary substrate for wine oxidation, although wines can vary tremendously in phenolic content and composition. Reduction potentials vary among different phenolic compounds (Kilmartin et al. 2001, 2002, Danilewicz 2003, 2012), and studies conducted in non-wine matrices have demonstrated that the structure of phenolic compounds can affect their ability to complex with and reduce iron(III) (Moran et al. 1997, Mira et al. 2002).

In addition to evaluating the effects of phenolic structure on the rate of iron(III) reduction in wine conditions, this investigation also aimed to examine the relationship between iron(III) reduction and oxygen consumption. High $\mathrm{pH}$ wines are thought to oxidize more readily than low $\mathrm{pH}$ wines (Rossi and Singleton 1966, Singleton 1987), and oxygen consumption has been found to occur more quickly in model wine at pH 6.97 than at pH 3.6 (Danilewicz 2011), though such an evaluation within the range of typical wine $\mathrm{pH}$ (3.0 to 4.0) has not been performed. Copper is another factor that accelerates oxygen uptake and is thought to catalyze the reaction between iron(II) and oxygen, though the precise mechanism of this interaction is uncertain (Danilewicz 2003, 2013, Danilewicz and Wallbridge 2010). Given the cyclic nature of iron's role in the wine oxidation mechanism, $\mathrm{pH}$ and copper may affect the recycling of iron(II) from iron(III) by phenols, thereby indirectly dictating the rate of oxygen consumption as a consequence. It was hypothesized that the rate at which oxygen is consumed depends on the rate at which iron(II) is replenished by phenols; thus, conditions that accelerate iron(III) reduction also accelerate oxygen consumption. To test this hypothesis, we evaluated and compared the kinetics of these two processes to ascertain which reaction is rate-determining for the wine oxidation pathway.

\section{Materials and Methods}

Chemicals and reagents. Iron(III) chloride hexahydrate, L-(+)-tartaric acid, 3-(2-pyridyl)-5,6-diphenyl-1,2,4-triazinep,p'-disulfonic acid monosodium salt (ferrozine), and ethyl- enediaminetetraacetic acid (EDTA) disodium salt dihydrate were purchased from Sigma-Aldrich. L-ascorbic acid and 4-methylcatechol were purchased from Aldrich Chemical Co., Inc. Sodium hydroxide and copper(II) sulfate pentahydrate were purchased from Fisher Scientific. Pyrogallol was purchased from HM Chemical Co., Ltd. Benzenesulfinic acid sodium salt was purchased from Acros Organics. Ethanol (200 proof) was purchased from Decon Labs. All chemicals used were of reagent grade.

Solutions of sodium hydroxide (5 N), iron(III) chloride (10.0 mM), copper(II) sulfate $(1.0 \mathrm{mM})$, and ferrozine $(3.5 \%$ $\mathrm{m} / \mathrm{v})$ were prepared in water. The EDTA $(0.005 \% \mathrm{~m} / \mathrm{v})$ and ascorbic acid $(0.1 \% \mathrm{~m} / \mathrm{v})$ solutions were prepared in model wine, which consisted of ethanol $(12 \% \mathrm{v} / \mathrm{v})$ and tartaric acid $(8 \mathrm{~g} / \mathrm{L})$ in water adjusted to $\mathrm{pH} 3.5$ using sodium hydroxide $(5 \mathrm{~N})$. Deionized water purified using a Milli-Q Synthesis A10 system from Millipore was used in the preparation of all solutions.

Reduction of iron(III). Model wines were prepared as above, though additional components were included and $\mathrm{pH}$ was adjusted according to the experimental treatments described below. The prepared wines were portioned $(100-\mathrm{mL}$ aliquots) into $125-\mathrm{mL}$ glass serum bottles from Sigma-Aldrich. The bottles were fashioned with SP-PSt3-NAU oxygen sensors, which allowed for use of a Fibox 3 trace oxygen meter from PreSens to noninvasively monitor dissolved oxygen levels. The bottles were wrapped in black electrical tape to exclude light and sealed with aluminum crimp caps with polytetrafluoroethylene/butyl septa from Agilent Technologies, through which further sample manipulations could take place.

Nitrogen gas from Praxair was used to purge the samples of oxygen and was delivered through bottle septa via deflected point, 22-gauge stainless steel needles from Cadence Science; secondary outlet needles allowed air to escape. When anoxic conditions $(<0.06 \mathrm{mg} / \mathrm{L}$ dissolved oxygen) were achieved, iron(III) was added $(0.1 \mathrm{mM})$ to start the reaction by injecting $1 \mathrm{~mL}$ of iron(III) chloride solution $(10 \mathrm{mM})$. Extraction of samples for iron speciation $(1.0 \mathrm{~mL})$ was performed using needle and syringe and took place periodically over $3 \mathrm{hr}$ to track the reduction of iron(III) to iron(II). Oxygen levels were monitored to verify the integrity of septa in preventing oxygen ingress throughout sampling. Experiments took place at room temperature $\left(22.2 \pm 0.4^{\circ} \mathrm{C}\right)$ and were conducted in triplicate.

Effects of phenolic structure and benzenesulfinic acid. Either 4-methylcatechol or pyrogallol were included during model wine preparation at $1.0 \mathrm{mM}$ with and without equimolar benzenesulfinic acid. The $\mathrm{pH}$ of these wines was adjusted to 3.5 using sodium hydroxide $(5 \mathrm{~N})$.

Effects of $\mathrm{pH}$ and copper. The model wine system of 4-methylcatechol $(1.0 \mathrm{mM})$ and benzenesulfinic acid $(1.0 \mathrm{mM})$ was further studied at $\mathrm{pH} 3.0$ and 4.0, in addition to $\mathrm{pH}$ 3.5. At each of these three $\mathrm{pH}$ levels, samples were prepared with and without copper $(0.01 \mathrm{mM})$. Copper additions took place by injecting $1 \mathrm{~mL}$ of copper(II) sulfate solution $(1.0 \mathrm{mM})$ through bottle septa immediately prior to the injection of iron(III).

Oxygen consumption. Model wines were prepared with 4-methylcatechol (1.0 $\mathrm{mM})$, benzenesulfinic acid (1.0 $\mathrm{mM})$, 
and iron(III) $(0.1 \mathrm{mM})$ as described above at $\mathrm{pH} 3.0,3.5$, and 4.0 with and without copper $(0.01 \mathrm{mM})$. The wines were saturated with air and transferred into $300-\mathrm{mL}$ biological oxygen demand bottles (DWK Life Sciences Wheaton) leaving no headspace. The samples were prepared in triplicate and stored in the dark at room temperature $\left(22.2 \pm 0.4^{\circ} \mathrm{C}\right)$. Dissolved oxygen levels were measured periodically over several days via PreSens sensors and oxygen meter to track consumption.

Spectrophotometric iron speciation. Upon sample extraction, analysis was performed using a previously described spectrophotometric method for iron speciation in wine (Nguyen and Waterhouse 2019), using the procedures for analysis of white wines. An Agilent Technologies 8453 spectrophotometer was used for measurements and operated using $845 \times$ UV-visible Chemstation software v. A.10.01[81]. Measurements were taken in disposable, semi-microvolume $(3.0 \mathrm{~mL}), 1.0-\mathrm{cm}$ path length, acrylic cuvettes from Sarstedt.

For the determination of iron(II), the samples $(1.0 \mathrm{~mL})$ were transferred into cuvettes containing $10 \mu \mathrm{L}$ ferrozine $(3.5 \% \mathrm{~m} / \mathrm{v})$ and mixed briefly, immediately after which 1500 $\mu \mathrm{L}$ EDTA $(0.005 \% \mathrm{~m} / \mathrm{v})$ was added. For total iron analysis (performed once initially in a separate cuvette to verify iron had been correctly added to each sample at $0.1 \mathrm{mM}$ ), 1500 $\mu \mathrm{L}$ ascorbic acid $(0.1 \% \mathrm{~m} / \mathrm{v})$ was used in place of EDTA. All absorbance measurements were taken at $562 \mathrm{~nm}$ against a model wine blank. Concentrations were calculated using an external calibration curve generated from a series of iron(II) standards in model wine ( 0.001 to $0.1 \mathrm{mM}$ ) measured in triplicate. Iron(III) levels were calculated by subtracting iron(II) from total iron.

Reaction order and rate constant determination. Reaction orders for iron(III) reduction and oxygen consumption were determined by plotting traces of these processes over time. All replicate data from each experimental treatment was included for linear least-squares regression analysis, which was performed using Microsoft Excel v. 16.14. Rate constants $(\mathrm{k})$ were calculated from the slope of lines best fit to the data on the basis of maximizing coefficients of determination $\left(\mathrm{R}^{2}\right)$.

\section{Results and Discussion}

Differential phenolic reactivity with iron(III). The level of iron used here $(0.1 \mathrm{mM})$ approximates the global average concentration of iron in wine $(5.5 \mathrm{mg} / \mathrm{L})$ (Danilewicz 2007). The model phenols, 4-methylcatechol or pyrogallol, were included at $1.0 \mathrm{mM}$ to ensure a molar excess relative to iron while also approximating the typical total phenolic content of white wines. Anoxic conditions were maintained throughout to enable monitoring of iron(III) reduction without interference from iron(II) oxidation.

In model wine at $\mathrm{pH} 3.5,4$-methylcatechol was unable to reduce iron(III) to a significant extent without aid from a nucleophile, with only $0.004 \mathrm{mM}$ iron(II) detected by the end of the experiment (Figure 2). Pyrogallol reduced iron(III) to a greater extent, although iron(II) levels also appeared to plateau in the absence of a nucleophile and reached $0.033 \mathrm{mM}$ by the end of the experiment. In tartrate buffer at $\mathrm{pH} 3.5$, the reduction potential $\left(\mathrm{E}_{3.5}\right)$ of the iron(III)/iron(II) couple is 360 $\mathrm{mV}$ (Green and Parkins 1961, Danilewicz 2003), while $\mathrm{E}_{3.5}$ values for the quinone/4-methylcatechol and quinone/pyrogallol couples are 547 and $474 \mathrm{mV}$, respectively. These values were calculated from data derived from polarographic measurements performed in phosphate buffer at $\mathrm{pH} 6.72$ (Horner and Geyer 1965), based on the knowledge that the reduction potential of phenolic compounds decreases by $59 \mathrm{mV}$ per $\mathrm{pH}$ unit increase (Kilmartin et al. 2001, Danilewicz 2003, 2012). At $\mathrm{pH} 3.5$, the cell potential (or potential difference, $\Delta \mathrm{E}_{3.5}$ ) for the reduction of iron(III) is therefore $-187 \mathrm{mV}$ for 4-methylcatechol and $-114 \mathrm{mV}$ for pyrogallol. Negative values correspond to a positive change in Gibbs free energy (Equation 1); thus, neither reaction is spontaneous in the forward direction, as evidenced here.

$$
\Delta \mathrm{G}=-\mathrm{nF} \Delta \mathrm{E}
$$

In this equation, $\Delta \mathrm{G}$ is the change in Gibbs free energy, $\mathrm{n}$ is number of electrons transferred, and $\mathrm{F}$ is the Faraday constant.

Iron(II) levels began to plateau at $30 \mathrm{~min}$; therefore, concentrations at this timepoint were used to estimate equilibrium constants $\left(\mathrm{K}_{\text {eq }}\right)$ for the reduction of iron(III) by 4-methylcatechol (Reaction 1) and pyrogallol (Reaction 2) in the absence of benzenesulfinic acid. The stoichiometry of these reactions presumes two moles of iron(III) are reduced for each

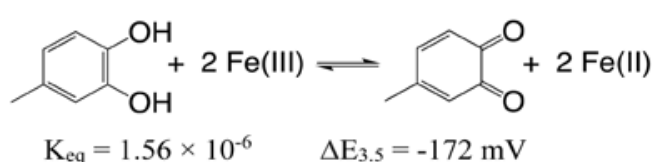

(Reaction 1)

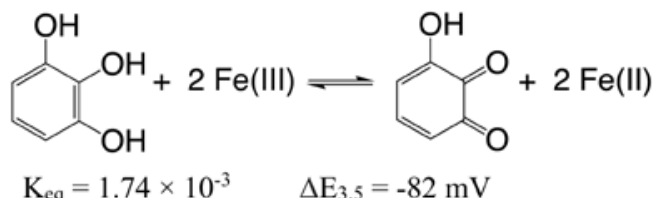

(Reaction 2)

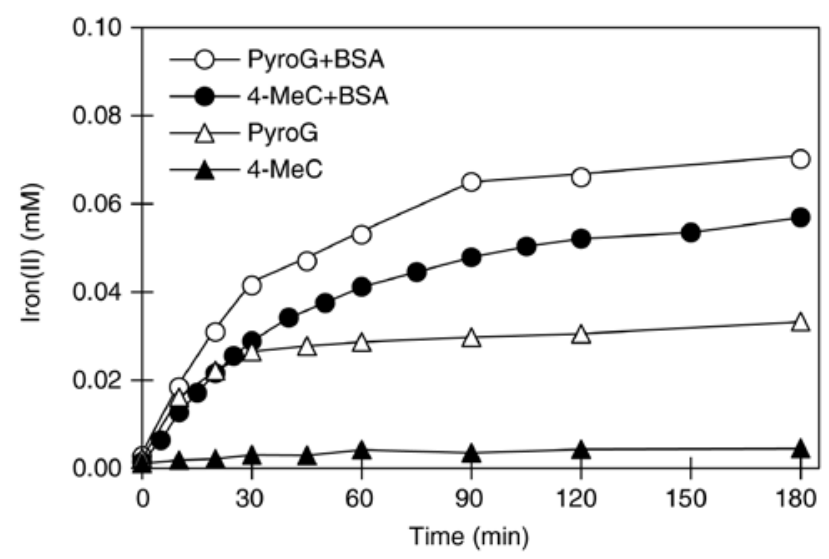

Figure 2 Iron(II) formation from iron(III) $(0.1 \mathrm{mM})$ in anoxic model wine ( $12 \%$ ethanol, $8 \mathrm{~g} / \mathrm{L}$ tartaric acid, $<0.06 \mathrm{mg} / \mathrm{L}$ dissolved oxygen) with 4-methylcatechol (4-MeC) or pyrogallol (PyroG) $(1.0 \mathrm{mM})$ in the absence and presence of equimolar benzenesulfinic acid (BSA) at pH 3.5. Standard deviations at each time point did not exceed $0.002 \mathrm{mM}$ iron(II) $(n=3)$. 
mole of phenol oxidized. The Nernst equation (Equation 2)

$$
\Delta \mathrm{E}=\frac{\mathrm{RT}}{\mathrm{nF}} \ln \mathrm{K}_{\mathrm{eq}}
$$

was used to calculate $\Delta \mathrm{E}_{3.5}$ for these reactions from their observed $\mathrm{K}_{\mathrm{eq}}$ values. In this equation, $\mathrm{R}$ is the gas constant and $\mathrm{T}$ is absolute temperature, while $\mathrm{n}$ and $\mathrm{F}$ are defined as above. Using $360 \mathrm{mV}$ as $\mathrm{E}_{3.5}$ for iron(III)/iron(II), values for the quinone/4-methylcatechol and quinone/pyrogallol couples can be calculated from $\Delta \mathrm{E}_{3.5}$ for Reactions 1 and 2 , and the experimentally determined values here for $\mathrm{E}_{3.5}$ were $532 \mathrm{mV}$ for quinone/4-methylcatechol and $442 \mathrm{mV}$ for quinone/pyrogallol. It should be noted that the equilibrium constants used in calculating these reduction potentials were estimates, and while these values are comparable to the aforementioned values calculated from polarography, discrepancies may be explained by the instability of quinones preventing true equilibrium between oxidation and reduction (Kilmartin et al. 2001).

In both cases when benzenesulfinic acid was included, iron(III) reduction was unrestricted (Figure 2). Other studies have demonstrated that oxygen consumption in model wines cannot occur without presence of a nucleophile to react with quinones as they are produced, thereby allowing phenol oxidation to occur in the thermodynamically disfavored forward direction per Le Chatelier's principle (Danilewicz 2003, 2011, Danilewicz et al. 2008, Danilewicz and Wallbridge 2010). The observations here reaffirm the function of nucleophiles in wine oxidation to aid phenols in providing the requisite iron(II) for oxygen consumption. Benzenesulfinic acid is not found naturally in wine but was used here as a model nucleophile, as has been done in previous studies to trap quinones (Cheynier et al. 1989, Danilewicz et al. 2008). The concentration used, equimolar to 4-methylcatechol or pyrogallol $(1.0 \mathrm{mM})$, ensured all potential quinones could be effectively captured. Different wine nucleophiles, including glutathione, thiols, phloroglucinol (representing the A-ring of flavonoids), and amino acids, have been found to react at different rates with the quinone of 4-methylcatechol in model wine (Nikolantonaki and Waterhouse 2012). Notably, sulfur dioxide reacts more slowly than benzenesulfinic acid (Danilewicz et al. 2008). The ability of nucleophiles to trap quinones may be a factor in determining the rate of iron redox cycling (Danilewicz 2011). Therefore, results may differ if a different nucleophile and concentration had been used, and future studies should investigate this possibility.

The greater reactivity of pyrogallol in comparison to 4-methylcatechol in the presence and absence of benzenesulfinic acid suggests phenolic structure has a significant effect on the rate of iron(III) reduction regardless of the nucleophile. The lower reduction potential of pyrogallol means it more readily loses electrons to iron(III), attributable to its third hydroxyl group, which confers additional stability to the semiquinone radical intermediate formed prior to the quinone (Waterhouse and Laurie 2006). Furthermore, electron transfer from phenols to iron(III) requires the formation of a transient iron(III)-phenolate complex from which the oxidized semiquinone/quinone and reduced iron(II) are subsequently released (Mentasti and Pelizzetti 1973, Hynes and Coinceanainn 2001, Perron and Brumaghim 2009). The third hydroxyl group of pyrogallol likely also aids in the formation of this complex with iron(III).

However, wine ageability may not be a matter of kinetics. If reactions were monitored for a much longer period of time (Figure 2), the difference between the reaction rates of pyrogallol and 4-methylcatechol would become immaterial, as both would eventually reduce the same amount of iron(III) provided a nucleophile such as benzenesulfinic acid is available. Pyrogallol serves as a model for 1,2,3-trihydroxy phenols (e.g., epigallocatechin and myricetin), and 4-methylcatechol serves as a model for ortho-dihydroxy phenols (e.g., caffeic acid and catechin); however, monohydroxy, meta-dihydroxy, and methoxy-substituted phenols are not represented here and are not as readily oxidized due to their inability to form stable semiquinones (Waterhouse and Laurie 2006). Cyclic and linear sweep voltammetry have been used to distinguish such phenolic fractions in wine based on their oxidizability. Findings have shown that readily oxidized phenols constitute only a portion of the total phenolic content in wines (Kilmartin et al. 2001, 2002, Ugliano 2016); therefore, measures of total phenolic content (e.g., Folin-Ciocalteu assay, absorbance at $280 \mathrm{~nm}$ ) likely do not reflect the oxidative capacity of wines.

Phenolic reactivity may still be diagnostic of wine age and ageability. Voltammetric analysis of wines has revealed anodic peak current intensities at certain voltages decrease with age and/or oxygen exposure, suggesting the exhaustion of oxidizable substrate (Kilmartin et al. 2002, Rodrigues et al. 2007, Martins et al. 2008, Gonzalez et al. 2018). Attending expressly to the reaction of phenols in the oxidation pathway, their ability to reduce iron(III) may similarly reflect wine age, as findings from a recent iron speciation study showed that while the majority of wines evaluated under continuous aerial oxygenation were able to maintain a non-zero level of iron(II), one much older wine that had been stored in a plastic bottle was unable to prevent the complete oxidation of iron(II) to iron(III) (Nguyen and Waterhouse 2019). However, the results here with regard to the effects of benzenesulfinic acid suggest the loss of phenolic reactivity could also be attributed to the depletion of nucleophiles, which evidently can play a similarly significant role as phenolic compounds in wine oxidation. Therefore, if wine age and ageability are to be evaluated quantitatively, accounting for the differential reactivity of phenolic compounds and their dependence on nucleophiles remains a challenge. A measurement of a wine's reactivity with iron, similar in principle to the ferric reducing antioxidant power assay (Benzie and Strain 1996, Katalinic et al. 2004), warrants further investigation as a potential way of assessing oxidizability.

Iron(III) reduction rates. Despite the 10-fold molar excess of 4-methylcatechol relative to iron(III), reduction of iron(III) in the presence of benzenesulfinic acid could not be neatly characterized as a pseudo-first order reaction with respect to iron(III) based on linear regression analysis of the decline in iron(III) over time, and the reaction also did 
not fit zeroth- or second-order kinetics. However, the natural $\log$ graphs of iron(III) reduction exhibited two distinct linear phases as shown for $\mathrm{pH} 3.5$ (Figure 3), which suggests that the reduction of iron(III) here is biexponential. Such kinetics may be attributed to two processes occurring together upon the addition of iron(III) to the system: while 4-methylcatechol can initially reduce iron(III) at a particular rate, complexation of iron(III) by tartrate gradually decelerates this reaction. Given that the electron transfer from 4-methylcatechol to iron(III) is predicated upon complex formation, its rate of reaction with iron(III) is likely dampened by competition from tartrate for the coordination sites of iron(III). Separate rate constants (k1 and $\mathrm{k} 2$ ) were calculated for the two phases of iron(III) reduction for each experimental treatment under the presumption of pseudo-first order kinetics for the individual phases (Table 1).

It is worth noting that the reaction between benzenesulfinic acid and the quinone of 4-methylcatechol produces an adduct with regenerated dihydroxy functionality (Reaction 3) (Danilewicz et al. 2008) that is capable of reacting again

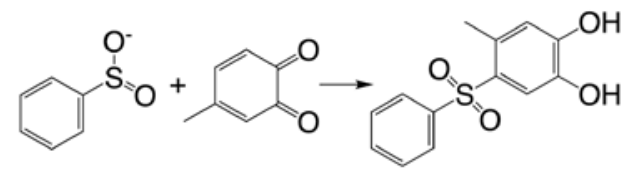

(Reaction 3)

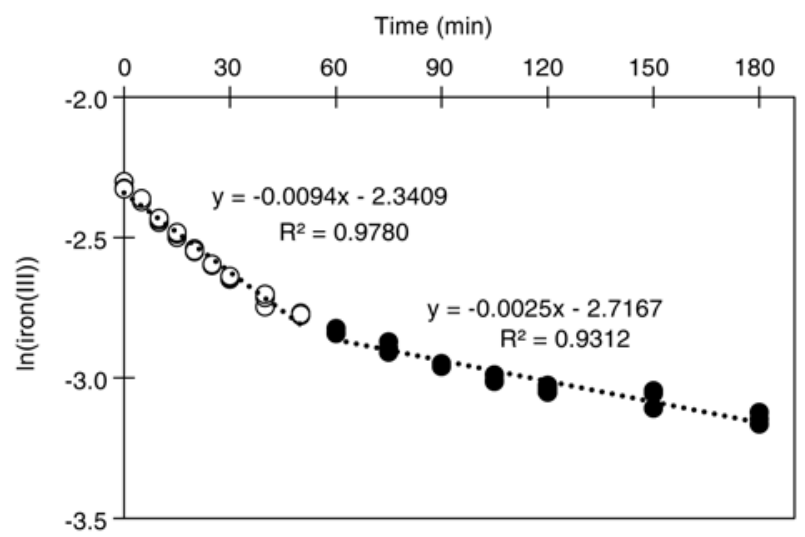

Figure 3 Natural log of iron(III) reduction $(0.1 \mathrm{mM})$ in anoxic model wine (12\% ethanol v/v, $8 \mathrm{~g} / \mathrm{L}$ tartaric acid, $<0.06 \mathrm{mg} / \mathrm{L}$ dissolved oxygen) with 4-methylcatechol $(1.0 \mathrm{mM})$ and benzenesulfinic acid $(1.0 \mathrm{mM})$ at $\mathrm{pH} 3.5$ $(n=3)$.

Table 1 Rate constants (1/min) for iron(III) reduction and oxygen consumption in model wine $(12 \%$ ethanol v/v, $8 \mathrm{~g} / \mathrm{L}$ tartaric acid) containing 4-methylcatechol $(1.0 \mathrm{mM})$ and benzenesulfinic acid $(1.0 \mathrm{mM})$. $\mathrm{k} 1$ and $\mathrm{k} 2$ are the respective rate constants for the first and second phases of iron(III) reduction caused by tartrate complexation.

\begin{tabular}{|c|c|c|c|c|c|}
\hline \multirow[b]{2}{*}{ pH } & \multirow{2}{*}{$\begin{array}{c}\text { Copper } \\
\text { (mM) }\end{array}$} & \multicolumn{3}{|c|}{ Iron(III) reduction } & \multirow{2}{*}{$\begin{array}{c}\begin{array}{c}\text { Oxygen } \\
\text { consumption }\end{array} \\
\mathbf{k}\end{array}$} \\
\hline & & k1 & k2 & $(k 1+k 2) / 2$ & \\
\hline \multirow[t]{2}{*}{3.0} & - & 1.7E-02 & 4.7E-03 & 1.1E-02 & $7.5 \mathrm{E}-05$ \\
\hline & 0.01 & 1.6E-02 & $3.1 \mathrm{E}-03$ & $9.5 \mathrm{E}-03$ & $3.9 \mathrm{E}-04$ \\
\hline \multirow[t]{2}{*}{3.5} & - & $9.4 \mathrm{E}-03$ & $2.5 \mathrm{E}-03$ & 6.0E-03 & $1.4 \mathrm{E}-04$ \\
\hline & 0.01 & $1.0 \mathrm{E}-02$ & 3.0E-03 & 6.6E-03 & $5.5 \mathrm{E}-04$ \\
\hline \multirow[t]{2}{*}{4.0} & - & 7.5E-03 & $2.4 \mathrm{E}-03$ & $5.0 \mathrm{E}-03$ & 2.9E-04 \\
\hline & 0.01 & 7.6E-03 & $2.5 \mathrm{E}-03$ & 5.1E-03 & 7.5E-04 \\
\hline
\end{tabular}

with iron(III). The effect of the benzenesulfinate group on the reactivity of this adduct is unclear, although the effect here on the observed rate of iron(III) reduction is expected to be insignificant because the original 4-methylcatechol is present at a much higher concentration relative to the adduct. Electron-withdrawing or sterically bulky nucleophiles in wine produce less reactive adducts, the buildup of which over time may contribute to the loss of ageability.

The reduction potential of quinone/phenol couples decreases as $\mathrm{pH}$ increases because quinone formation entails the loss of electrons and protons (Kilmartin et al. 2001, Danilewicz 2003, 2012). Furthermore, the anionic phenolate forms of phenolic compounds, more prevalent in alkaline conditions, are thought to be more susceptible to oxidation than their protonated conjugates (Rossi and Singleton 1966, Singleton 1987). Based on this information, electron transfer to iron(III) was expected to occur more quickly with higher $\mathrm{pH}$, although the rate of iron(III) reduction by 4-methylcatechol in the presence of benzenesulfinic acid was lower at $\mathrm{pH}$ 4.0 than at $\mathrm{pH} 3.0$ (Table 1, Figure 4). These results suggest the proportion of phenolates is not significant to wine oxidation in this $\mathrm{pH}$ range. While the reduction potential for the quinone/4-methylcatechol couple decreases by $59 \mathrm{mV}$ per $\mathrm{pH}$ unit increase, that of the iron(III)/iron(II) couple decreases by $130 \mathrm{mV}$ per $\mathrm{pH}$ unit increase (Green and Parkins 1961). Due to increased deprotonation of tartaric acid into tartrate, which preferentially stabilizes iron(III) over iron(II) (Timberlake 1964, Danilewicz 2014), $\Delta \mathrm{E}$ for the reaction becomes increasingly negative with higher $\mathrm{pH}$. Reduction potentials appear to predict reaction rates for $\mathrm{pH}$-dependent redox reactions (Michaelis and Smythe 1931, Smythe 1931), although they are a thermodynamic property and should not be used to explain reaction rates, which describe kinetics.

While phenolates do become more abundant with higher $\mathrm{pH}$, the effective concentration of iron(III) may be lowered due to tartrate complexation. Dimeric and trimeric iron(III)tartrate complexes, which are more prevalent with higher $\mathrm{pH}$ (Timberlake 1964, Yokoi et al. 1994), may be particularly

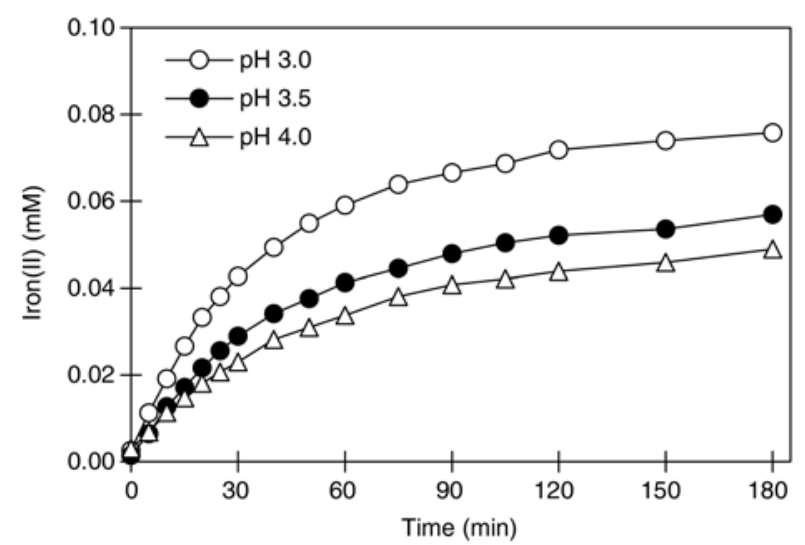

Figure 4 Iron(II) formation from iron(III) $(0.1 \mathrm{mM})$ in anoxic model wine ( $12 \%$ ethanol, $8 \mathrm{~g} / \mathrm{L}$ tartaric acid, $<0.06 \mathrm{mg} / \mathrm{L}$ dissolved oxygen) with 4-methylcatechol $(1.0 \mathrm{mM})$ and benzenesulfinic acid $(1.0 \mathrm{mM})$ at various $\mathrm{pH}$. Standard deviations at each time point did not exceed 0.002 $\mathrm{mM}$ iron(II) $(\mathrm{n}=3)$. 
effective at blocking phenols from complexing and reacting with iron(III). Furthermore, the occurrence of intra-complex electron transfer has been found to be $\mathrm{pH}$-dependent. While mono (1:1) iron(III)-phenolate complexes predominate in acidic conditions $(\mathrm{pH}<4.0)$ and are redox-active, the bis $(1: 2)$ and tris $(1: 3)$ complexes arising in more basic conditions appear to be stable against redox decomposition (Avdeef et al. 1978, Powell and Taylor 1982, Hider et al. 2001, Perron and Brumaghim 2009). The stability of such complexes in alkaline conditions provides the basis for the ferric chloride test for phenols, which is used in the Adams-Harbertson assay for tannin quantification in wine (Harbertson et al. 2003), and may explain in part the diminished rate of iron(III) reduction observed at higher $\mathrm{pH}$.

The level of copper used here $(0.01 \mathrm{mM})$ equates to 0.6 $\mathrm{mg} / \mathrm{L}$ and constitutes an extreme scenario in which the legal limit for residual copper in wine $(0.5 \mathrm{mg} / \mathrm{L})$, as defined in the United States Code of Federal Regulations (\$24.246), was exceeded. The inclusion of copper at this concentration did not discernibly affect the rate of iron(III) reduction at any of the three $\mathrm{pH}$ levels (Table 1), despite previous studies showing that copper increased rates of oxygen consumption (Danilewicz and Wallbridge 2010, Danilewicz 2013).

Oxygen consumption rates. In monitoring oxygen levels in air-saturated model wines of the same compositions as above, rates of oxygen consumption increased with higher $\mathrm{pH}$ and with the inclusion of copper (Table 1), disproving our hypothesis that rates of oxygen consumption and phenol oxidation are linked. These two processes may be coupled by the redox cycling of iron but do not necessarily occur synchronously. Faster oxygen consumption observed with higher $\mathrm{pH}$ may be attributed to iron(II) oxidation independent of its recycling from iron(III) by phenols. Although tartrate forms more stable complexes with iron(III), complexes with iron(II) also become more abundant as $\mathrm{pH}$ increases. The extraction of an electron from an electrically neutral iron(II)-tartrate complex is far less energetically demanding than the oxidation of a free iron(II) cation (Michaelis and Smythe 1931, Smythe 1931). With regard to the effects of copper, these findings indicate it facilitates the reaction between iron(II) and oxygen, as has been suggested previously, but not the reaction between iron(III) and phenols. The precise mechanism by which copper catalyzes the oxidation of iron(II) has yet to be determined, although copper may also participate in redox cycling by coupling iron(II) oxidation to the reduction of oxygen, or it may form a cationic copper(I)-dioxygen intermediate that more readily oxidizes iron(II) (Danilewicz 2007). The formation of a binuclear iron-copper complex capable of reacting more rapidly with oxygen is also possible (Danilewicz and Wallbridge 2010). In previous studies attempting to correlate rates of oxygen consumption with the chemical compositions of red, white, and rosé wines, $\mathrm{pH}$ and copper consistently exhibited a positive relationship with oxygen consumption. Interestingly, correlations with most other parameters, notably aspects of phenolic content and composition, were inconsistent or negative (Ferreira et al. 2015, Carrascon et al. 2017, 2018).
As has been reported previously in white wines (Gonzalez et al. 2018), oxygen consumption appeared to follow pseudo-first order kinetics, despite addition of iron to the model wines in the form of oxidized iron(III) at a concentration not in excess relative to the initial concentration of oxygen at air-saturation. In the abovementioned correlational studies employing repeated air-saturation cycles (Ferreira et al. 2015, Carrascon et al. 2017), reaction order was not determined but the kinetics of oxygen uptake were consistent upon each saturation, which, according to the study authors, implies that iron(III) is "spontaneously" reduced at the end of each cycle. However, the direct oxidation of iron(II) by oxygen is not the only means by which oxygen is consumed in the wine oxidation pathway. After formation of hydrogen peroxide and the Fenton oxidation of ethanol, oxygen can add to the intermediate 1-hydroxyethyl radical to form the 1-hydroxyethylperoxyl radical, which ultimately decomposes to yield acetaldehyde (Elias and Waterhouse 2010). Given the catalytic role of iron(II) in the Fenton reaction, this secondary point of entry for oxygen still constitutes the oxidation of a molar equivalent of iron(II), albeit indirectly. The effects of wine composition on the rates of these reactions remain to be elucidated.

The results here in the model system of 4-methylcatechol and benzenesulfinic acid confirm that a supply of iron(II) can be effectively maintained so as not to limit the rate of oxygen consumption, as the rate constants for iron(III) reduction were significantly higher than those for oxygen consumption in all cases (Table 1). While the effect of different nucleophiles on the rate of iron(III) reduction is unclear, sulfur dioxide significantly decreases the rate of oxygen consumption. The difference in rate constants would be even more apparent, as the quenching of hydrogen peroxide by sulfur dioxide would eliminate post-Fenton reaction oxygen consumption and increase the availability of iron(II). Together with our results, this suggests iron(II) oxidation is the ratedetermining reaction for the wine oxidation pathway. However, the ability of wine to reduce iron(III) likely declines as it ages, whether by exhaustion of phenols or of nucleophiles, such that it eventually limits the rate of oxygen consumption.

The relative rates of iron oxidation and reduction may explain the poor correlation noted previously between oxygen consumption and wine composition, as well as the high iron(II):iron(III) ratios (Danilewicz 2016, 2018, Nguyen and Waterhouse 2019) and low oxygen levels (Castellari et al. 2004, del Alamo-Sanza and Nevares 2014, 2018, Vidal et al. 2017) commonly observed for wines in storage. Evidently, wine effectively maintains reductive conditions, and oxygen is very rarely in constant excess (e.g., defective closures or packaging). Thus, wine is constantly primed to receive more oxygen and therefore ages at a rate limited by oxygen ingress and not by the reactions therein (Danilewicz 2018). The outcome of oxidation varies among wines, given that the accumulation of different chemical products responsible for changes to color, flavor, and mouthfeel is a function of initial composition. However, variability in the rate at which wines undergo such changes may be attributed largely to differences 
in oxygen ingress, which initiates iron(II) oxidation and determines the rate for the remainder of the pathway.

\section{Conclusion}

Factors influencing the rate of the redox reaction between iron(III) and phenols were investigated for the first time in wine conditions. 4-Methylcatechol and pyrogallol, models for ortho-dihydroxy and 1,2,3-trihydroxy phenols, respectively, differed in their ability to reduce iron(III), illustrating how reactivity can vary with molecular structure. The phenolic compounds in wine are not equally oxidizable; thus, typical measures of total phenolic content are likely inadequate indicators of oxidizability. Furthermore, the model nucleophile benzenesulfinic acid was required for thermodynamically unrestricted reduction of iron(III) to occur with either phenolic compound, indicating wine oxidation may be limited by the availability of nucleophiles (e.g., glutathione or condensed tannin), and their exhaustion may preclude further reactions. Attempts to assess wine ageability must therefore take into account both the differential reactivity of phenols and the dependence of oxidation reactions on nucleophiles.

The rate of iron(III) reduction by 4-methylcatechol in the presence of benzenesulfinic acid was lower at higher $\mathrm{pH}$, which may be attributed to competition from tartrate for the coordination sites of iron(III) and/or the formation of redox-stable iron(III)-phenolate complexes at higher $\mathrm{pH}$. Copper had no discernible effect on the rate of iron(III) reduction. Despite the coupling of oxygen reduction and phenol oxidation by iron, the hypothesis that rates of oxygen consumption depend on the recycling of iron by phenols was disproven, as oxygen consumption occurred more quickly at higher $\mathrm{pH}$ and with the inclusion of copper. The pseudo-first order rate constants determined for oxygen consumption were lower than those of iron(III) reduction in all cases studied, suggesting iron(II) oxidation was the rate-determining reaction of the wine oxidation pathway.

Given that oxygen is seldom in constant excess during winemaking and aging, future studies pertaining to wine ageability should focus on maximum quantity of oxygen consumption, perhaps before a particular chemical or sensory threshold is reached, rather than on rate of oxygen consumption. A measure of oxidation capacity that accounts for both phenolic and nucleophilic reactivity, based perhaps on the reduction of iron(III), is of interest.

\section{Literature Cited}

Avdeef A, Sofen SR, Bregante TL and Raymond KN. 1978. Coordination chemistry of microbial iron transport compounds. 9. Stability constants for catechol models of enterobactin. J Am Chem Soc 100:5362-5370.

Benzie IFF and Strain JJ. 1996. The ferric reducing ability of plasma (FRAP) as a measure of "antioxidant power": The FRAP assay. Anal Biochem 239:70-76.

Carrascón V, Bueno M, Fernandez-Zurbano P and Ferreira V. 2017. Oxygen and $\mathrm{SO}_{2}$ consumption rates in white and Rosé wines: Relationship with and effects on wine chemical composition. J Agric Food Chem 65:9488-9495.

Carrascón V, Vallverdú-Queralt A, Meudec E, Sommerer N, FernandezZurbano P and Ferreira V. 2018. The kinetics of oxygen and $\mathrm{SO}_{2}$ consumption by red wines. What do they tell about oxidation mechanisms and about changes in wine composition? Food Chem 241:206-214.

Castellari M, Simonato B, Tornielli GB, Spinelli P and Ferrarini R. 2004. Effects of different enological treatments on dissolved oxygen in wines. Ital J Food Sci 16:387-396.

Cheynier V, Basire N and Rigaud J. 1989. Mechanism of trans-caffeoyltartaric acid and catechin oxidation in model solutions containing grape polyphenoloxidase. J Agric Food Chem 37:1069-1071.

Danilewicz JC. 2003. Review of reaction mechanisms of oxygen and proposed intermediate reduction products in wine: Central role of iron and copper. Am J Enol Vitic 54:73-85.

Danilewicz JC. 2007. Interaction of sulfur dioxide, polyphenols, and oxygen in a wine-model system: Central role of iron and copper. Am J Enol Vitic 58:53-60.

Danilewicz JC. 2011. Mechanism of autoxidation of polyphenols and participation of sulfite in wine: Key role of iron. Am J Enol Vitic 62:319-328.

Danilewicz JC. 2012. Review of oxidative processes in wine and value of reduction potentials in enology. Am J Enol Vitic 63:1-10.

Danilewicz JC. 2013. Reactions involving iron in mediating catechol oxidation in model wine. Am J Enol Vitic 64:316-324.

Danilewicz JC. 2014. Role of tartaric and malic acids in wine oxidation. J Agric Food Chem 62:5149-5155.

Danilewicz JC. 2016. Fe(II):Fe(III) ratio and redox status of white wines. Am J Enol Vitic 67:146-152.

Danilewicz JC. 2018. [Fe(III)]:[Fe(II)] ratio and redox status of red wines: Relation to so-called "reduction potential." Am J Enol Vitic 69:141-147.

Danilewicz JC and Wallbridge PJ. 2010. Further studies on the mechanism of interaction of polyphenols, oxygen, and sulfite in wine. Am J Enol Vitic 61:166-175.

Danilewicz JC, Seccombe JT and Whelan J. 2008. Mechanism of interaction of polyphenols, oxygen, and sulfur dioxide in model wine and wine. Am J Enol Vitic 59:128-136.

Del Alamo-Sanza M and Nevares I. 2014. Recent advances in the evaluation of the oxygen transfer rate in oak barrels. J Agric Food Chem 62:8892-8899.

Del Alamo-Sanza M and Nevares I. 2018. Oak wine barrel as an active vessel: A critical review of past and current knowledge. Crit Rev Food Sci Nutr 58:2711-2726.

Elias RJ and Waterhouse AL. 2010. Controlling the Fenton reaction in wine. J Agric Food Chem 58:1699-1707.

Ferreira V, Carrascón V, Bueno M, Ugliano M and Fernandez-Zurbano P. 2015. Oxygen consumption by red wines. Part I: Consumption rates, relationship with chemical composition, and role of $\mathrm{SO}_{2}$. J Agric Food Chem 63:10928-10937.

Gonzalez A, Vidal S and Ugliano M. 2018. Untargeted voltammetric approaches for characterization of oxidation patterns in white wines. Food Chem 269:1-8.

Green MJ and Hill HAO. 1984. Chemistry of dioxygen. Method Enzymol 105:3-22.

Green RW and Parkins GM. 1961. Complexes of iron with D-tartaric and meso-tartaric acids. J Phys Chem 65:1658-1659.

Harbertson JF, Picciotto EA and Adams DO. 2003. Measurement of polymeric pigments in grape berry extracts and wines using a protein precipitation assay combined with bisulfite bleaching. Am J Enol Vitic 54:301-306.

Hider RC, Liu ZD and Khodr HH. 2001. Metal chelation of polyphenols. Method Enzymol 335:190-203. 
Horner L and Geyer E. 1965. Die polarographische bestimmung der redoxpotentiale von brenzcatechin-derivaten. Chem Ber 98:2009-2015.

Hynes MJ and Coinceanainn MO. 2001. The kinetics and mechanisms of the reaction of iron(III) with gallic acid, gallic acid methyl ester and catechin. J Inorg Biochem 85:131-142.

Katalinić V, Milos M, Modun D, Music I and Boban M. 2004. Antioxidant effectiveness of selected wines in comparison with $(+)$-catechin. Food Chem 86:593-600.

Kilmartin PA, Zou HL and Waterhouse AL. 2001. A cyclic voltammetry method suitable for characterizing antioxidant properties of wine and wine phenolics. J Agric Food Chem 49:1957-1965.

Kilmartin PA, Zou HL and Waterhouse AL. 2002. Correlation of wine phenolic composition versus cyclic voltammetry response. Am J Enol Vitic 53:294-302.

Kreitman GY, Cantu A, Waterhouse AL and Elias RJ. 2013. Effect of metal chelators on the oxidative stability of model wine. J Agric Food Chem 61:9480-9487.

Martins RC, Oliveira R, Bento F, Geraldo D, Lopes VV, de Pinho PG, Oliveira CM and Ferreira ACS. 2008. Oxidation management of white wines using cyclic voltammetry and multivariate process monitoring. J Agric Food Chem 56:12092-12098.

Mentasti E and Pelizzetti E. 1973. Reactions between iron(III) and catechol (o-dihydroxybenzene). 1. Equilibria and kinetics of complex formation in aqueous acid solution. J Chem Soc, Dalton Trans 2605-2608.

Michaelis L and Smythe CV. 1931. The correlation between rate of oxidation and potential in iron systems. J Biol Chem 94:329-340.

Miller DM, Buettner GR and Aust SD. 1990. Transition metals as catalysts of autoxidation reactions. Free Radical Bio Med 8:95-108.

Mira L, Fernandez MT, Santos M, Rocha R, Florêncio MH and Jennings KR. 2002. Interactions of flavonoids with iron and copper ions: A mechanism for their antioxidant activity. Free Radical Res 36:1199-1208.

Moran JF, Klucas RV, Grayer RJ, Abian J and Becana M. 1997. Complexes of iron with phenolic compounds from soybean nodules and other legume tissues: Prooxidant and antioxidant properties. Free Radical Biol Med 22:861-870.
Nguyen TH and Waterhouse AL. 2019. A production-accessible method: Spectrophotometric iron speciation in wine using ferrozine and ethylenediaminetetraacetic acid. J Agric Food Chem 67:680-687.

Nikolantonaki M and Waterhouse AL. 2012. A method to quantify quinone reaction rates with wine relevant nucleophiles: A key to the understanding of oxidative loss of varietal thiols. J Agric Food Chem 60:8484-8491.

Perron NR and Brumaghim JL. 2009. A review of the antioxidant mechanisms of polyphenol compounds related to iron binding. Cell Biochem Biophys 53:75-100.

Powell HKJ and Taylor MC. 1982. Interactions of iron(II) and iron(III) with gallic acid and its homologs: A potentiometric and spectrophotometric study. Aust J Chem 35:739-756.

Rodrigues A, Ferreira ACS, de Pinho PG, Bento F and Geraldo D. 2007. Resistance to oxidation of white wines assessed by voltammetric means. J Agric Food Chem 55:10557-10562.

Rossi JA and Singleton VL. 1966. Contributions of grape phenols to oxygen absorption and browning of wines. Am J Enol Vitic 17:231-239.

Singleton VL. 1987. Oxygen with phenols and related reactions in musts, wines, and model systems: Observations and practical implications. Am J Enol Vitic 38:69-77.

Smythe CV. 1931. The mechanism of iron catalysis in certain oxidations. J Biol Chem 90:251-265.

Timberlake CF. 1964. Iron-tartrate complexes. J Chem Soc 1229-1240.

Ugliano M. 2016. Rapid fingerprinting of white wine oxidizable fraction and classification of white wines using disposable screen printed sensors and derivative voltammetry. Food Chem 212:837-843.

Vidal JC, Caille S, Samson A and Salmon JM. 2017. Comparison of the effect of 8 closures in controlled industrial conditions on the shelf life of a red wine. In 40th World Congress of Vine and Wine. Aurand JM (ed.). BIO Web of Conferences:9:02024.

Waterhouse AL and Laurie VF. 2006. Oxidation of wine phenolics: A critical evaluation and hypotheses. Am J Enol Vitic 57:306-313.

Yokoi H, Mitani T, Mori Y and Kawata S. 1994. Complex formation between iron(III) and tartaric and citric acids in a wide $\mathrm{pH}$ range 1 to 13 as studied by magnetic susceptibility measurements. Chem Lett 23:281-284. 